\title{
The Skylab syndrome
}

There has been something deeply symbolic about Skylab's ungainly descent back down to earth. After all, it is almost ten years to the day since the US successfully carried out what many consider to represent the pinnacle of its scientific and technological achievement: placing a man on the surface of the moon. The deed did, indeed, turn out to be a turning point, but perhaps not in the way that those responsible for the lunar programme intended. For it took place on the eve of a decade in which mankind has turned its technological concerns away from the stars and back to its own planet, and to the more mundane, but no less complex, concerns such as health, energy and natural resources that have become the new prime targets for research. Skylab's demise comes on the eve of a new decade; and its message, which seems likely to become a dominant political theme in the years ahead, is that high technology frequently carries a built-in risk factor which, if not adequately planned for, will return to haunt us with its own particular form of revenge.

The whole incident could not have occurred at a worse time for the National Aeronautics and Space Administration. The agency's public image is currently being seriously tarnished by a set of technical problems, and related cost over-runs, in the space shuttle development programme. These problems have forced the agency, for the first time in many years, to go back to Congress cap in hand to request a substantial increase in funding over what had previously been agreed. With Congress already doing what it can to reduce expenditure across the whole federal budget, NASA's case has not been helped by an incident which links the agency directly to other areas of public concern over the dangers of high technology, in particular the Three Mile Island accident and the DC-10 aircrash. And although it seems likely that the extra money will be forthcoming - largely because of the military importance of space shuttle for launching satellites and carrying out surveillance tasks - other areas of NASA's activity may be made to suffer as a result.

At one level, both the problems with Skylab and the space shuttle can be attributed to the consequences of working with tight financial budgets. Skylab's designers saved $\$ 10$ to $\$ 20$ million by not adding engines that would have boosted the space station in its orbit when it began to slip back to earth, enabling it to be kept in orbit until it could be reached by space shuttle (the shuttle was initially expected to be launched this year, and Skylab to stay in orbit until 1983). And in the case of the shuttle itself, delays have been caused largely as a result of the development programme being planned according to a success-oriented strategy, with minimum back-up to allow for problems.

But it has not only been a question of money; there is also the question of control, and the associated attitude towards risktaking With space shuttle, the main contractor for the engine development has admitted to a certain laxity in overseeing the development of the programme, and has announced moves to remedy this situation by establishing close links between the technical and the financial staff. In Skylab's case that lack of adequate control, manifest in a more direct sense, has given rise to problems far too late for anything to be done.

The lesson of both would, in different ways, appear to be obvious: that in developing high technology with a potentially significant social impact, mechanisms to ensure adequate control of the technology should be developed at the same pace as the technology itself. The problem is that although this prognosis has logic on its side, it runs directly into conflict with the ideology of a system which rewards technological ingenuity rather than social responsibility. The market-place, rather than the political process, has been treated as the proper forum for weighing risks against benefits; and those who have introduced new technologies have, as a result, felt no responsibility for the way that purchasers choose to make use of them. Indeed a surfeit of regulation society's attempt to control the various non-market impacts of technology - has been increasingly criticised in recent years for its impact on the innovation process; and pressures are growing both in the US and, in line with the new government's current ideology, in the UK to return to the market place in its purest form as the prime regulatory agency.

Such programmes are, as their supporters point out, intentionally risky ones; only, they would argue, by encouraging people to take risks - and subsequently to reward those whose risks pay off - can vitality be reintroduced into the economic system. But such an approach is also predicated on the basis that the losers will suffer; and the particular concern generated by high technology is that the economic gains generated by the risk-taking of some will be outweighed, not so much by the losses of unsuccessful risk takers, but by the broader impact of failure upon those excluded from the decision-making on the risk in the first place.

What has concerned people most about Skylab is not so much the fact of its re-entry as the virtual total lack of control over its descent. Just as in the case of the Three Mile Island incident, it was the involuntary aspect of exposure to radiation emitted from the plant, rather than the actual level of exposure (compared, for example, to normal background radiation), that generated the fiercest complaints. Equally control cannot be reduced simply to a managerial or technical function, but must be seen to reflect a broad sense of responsibility to the whole community.

It would be a tragedy if the dominant message left by the Skylab incident, following as closely as it does the other high technology accidents that have occurred this year, merely frightened people away from such technology on principle. However if what comes through is that the control of technology is as important as the technology itself, then the lesson will have been worth-while. Perhaps this is the most significant theme to have emerged from recent debates about the concept of "appropriate" technologies, both in developed and developing countries; perhaps, too, it is one that we can learn to put into action in the decade ahead. 